\title{
Use of Anti-Inflammatory Agents by Pharmacy College Students: Correlation of the Menstrual Cycle and Self-medication
}

\author{
Jeimes Lennon Lopes Cândido ${ }^{1}$ *, Anne Karine Sousa Nóbrega Maia', Glaucia Maria Nogueira Cunha', Francisco Josimar Girão Junior ${ }^{1}$, \\ Marta Maria de França Fonteles ${ }^{2}$, José Márcio Machado Batista ${ }^{1}$ \\ 'Faculty of Pharmacy, Catholic University Center of Quixadá, Quixadá, Ceará, BRAZIL. \\ 2Department of Pharmacy, Federal University of Ceará, Fortaleza, Ceará, BRAZIL.
}

\section{ABSTRACT}

Aim: This study aims to evaluate the use of nonsteroidal anti-inflammatory drugs (NSAIDs) and factors associated with this practice as well as drugrelated problems and self-medication by pharmacy students of University Center Catholic of Quixadá, Ceará, Brazil. Methods: The prospective study with a quantitative approach was conducted. The participants were 96 female pharmacy students, who answered an e-mail questionnaire containing questions regarding the main NSAIDs used, pre-menstrual and menstrual use, drug-related problems and self-medication. Results: The results showed that students $>39$ years and in the 1st year of graduation had the lowest rates of use of NSAIDs, 33.3\% ( $p=0.0005)$ and $77.7 \%(p=0.01)$ respectively. The most commonly drug used were dipyrone $(64.5 \%)$ and paracetamol $(54.1 \%)$, mainly for painful processes such as headache $(68.7 \%)$ and colic $(62.5 \%)$. Self-medication was $92.7 \%$ those students, and the main side effects were nausea (14.5\%) and heartburn $(10.4 \%)$. There was greater use of anti-inflammatories among university students in the menstrual period, in those with irregular menstrual cycle and with a flow $<7$ days. Conclusion: In conclusion, NSAIDs are the most frequently
\end{abstract}

used drugs among students of female pharmacy colleges for algic processes such as headache, menstrual cramps, migraine and others referred to as possible hormonal changes. High self-medication was observed, which leads to frequent gastrointestinal adverse effects. Studies are still needed to evaluate the possible impacts of the use of these drugs in the medium and long term in this population.

Key words: Pharmacy, Menstrual cycle, Non-steroidal anti-inflammatory drugs, Self-medication, Students.

\section{Correspondence}

Mr. Jeimes Lennon Lopes Cândido, Rua Epitácio Pessoa, n 55, Alto São Francisco, Quixadá-CE, Brazil.

Phone: +55-88-999179985

Email: jeimescandido@gmail.com

DOI: 10.5530/jyp.2018.10.101

\section{INTRODUCTION}

The global pharmaceutical market is steadily growing, mainly due to the increase in sales in emerging countries, where it is expected to reach around US $\$ 1.4$ trillion by 2020 . Brazil jumped from $10^{\text {th }}$ to $7^{\text {th }}$ place between 2010 and 2015 in the ranking drug sales. ${ }^{1}$ According to a recent survey, the 2011 billing of medicines in Brazil was US \$ 25.8 billion, 70\% corresponding to prescription drugs and $30 \%$ to prescription-free. ${ }^{2}$

Non-steroidal anti-inflammatory drugs (NSAIDs) are drugs that have analgesic, antipyretic and anti-inflammatory therapeutic effect. Its pharmacological action occurs through the inhibition of cyclooxygenases (COXs), thus blocking the synthesis of prostaglandins and thromboxanes through arachidonic acid. ${ }^{3}$ They are routinely used for the treatment of fever, inflammations and algesic pictures in general such as cramps, headache, muscle pain, among others. ${ }^{4}$ The most common side effects are gastrointestinal. ${ }^{5-6}$

NSAIDs are one of the most prescribed pharmacological classes in the world. ${ }^{7}$ In Brazil, doctors prescribe these drugs quite a lot for their patients, in addition to some of them being purchased in pharmacies without the need for prescription. ${ }^{8}$ This easy access can lead to irrational consumption by self-medication by the population, thus its adverse effects may be more frequent and important, causing renal, hepatic, cardiac, haematological, gastrointestinal problems, among others. ${ }^{9}$

Studies show that women are the ones who use the most drugs and health services. ${ }^{10}$ Throughout their life women undergo high hormonal changes, beginning with menarche, then with the premenstrual and menstrual periods, and finally the menopause. ${ }^{11}$
In these phases, most of them present diverse algic states, many of them are believed to be due to unknown interactions between sex steroids, endogenous opioid peptides, central neurotransmitters, prostaglandins, and peripheral and endocrine autonomic systems. It has also been associated with vitamin B6 deficiency and excess prolactin. ${ }^{12}$

Frequent algic problems such as colic, headache, breast tenderness and other pains present in the premenstrual and menstrual periods may lead women to use NSAIDs in a chronic way for their good therapeutic efficacy, but this profile of use increases the chances of drug related problems (DRPs). ${ }^{13}$

Women are more susceptible to algic problems such as headache, migraine, dysmenorrhea due to the hormonal variations that occur in the menstrual cycle. ${ }^{14}$ In a study involving 571 university students, of these $74.6 \%$ women, they found a high rate of self-medication in graduation courses in Pharmacy, Medicine and Nursing, where approximately $88.3 \%$ used NSAIDs mainly for the relief of headache and pain in general. ${ }^{15}$ A survey evidenced a high index (95.4\%) of dysmenorrhea in university students, which leads to an absenteeism of their academic activities, resulting in a loss of productivity and a decrease in quality of life. ${ }^{16}$

Since these monthly algesic situations, mainly due to the hormonal changes that occur in the menstrual cycle, students of the Pharmacy undergraduate course can use NSAIDs in an irrational and unsafe way. The use of these drugs by these university students can cause some problem 
immediately, or lead to the development of complications arising from continuous use.

In this perspective, the study evaluated the use of anti-inflammatories by college students of the Pharmacy course at a higher education institution in the town of Quixadá-CE, identifying the most used and corresponding situations. It also verified self-medication and side effects presented after use in order to provide information to characterize the profile of the use of NSAIDs, in terms of rationality and safety, and to help guide awareness measures for rational use. Preventing so, health problems in the local female population, as chronic and insecure use can promote pathological changes that affect people's quality of life.

\section{METHODS}

The study is transversal, prospective, consisting of a quantitative approach. It was developed in a private university center (Quixadá Catholic University Center) and local reference in the interior of Ceará, Brazil. The studied population was composed by the female students of the course of graduation in pharmacy, regular in the institution during the period of collection and after updating the e-mails of these students. Students not enrolled in the semester during data collection, those with inactive e-mails, and those under 18 years of age were excluded. Dependent variables were analyzed as anti-inflammatory methods, reason for use, frequency, presence of some pathological condition, side effects, among others and independent socio-economic and demographic variables. Data was collected from in August 2016, based on an electronic questionnaire developed in Google Drive, which was sent to the students for their respective e-mails. Data were obtained through questions with simple or multiple choice objective responses and stored in the Google Drive database in a specific spreadsheet. Subsequently, a quantitative data analysis statistical was performed in Statistical Package for the Social Sciences (SPSS) 20.0 program. Logistic regression was used to evaluate association between graduation time and use of NSAIDs, considered significant the value of $p<0.05$.

\section{Ethical issues}

The study was submitted and approved by the Research Ethics Committee Quixadá Catholic University Center, with the opinion no. 1,558,657, in compliance with the recommendations of Resolution 466/12 of the National Health Council (BRAZIL), which regulates the guidelines and norms of the research in humans, preserving the identity of the study subjects.

\section{RESULTS}

The study was carried out with 145 women students from a university center in August 2016, where 103 students (71\%) answered the electronic questionnaire sent to their respective e-mails, 7 questionnaires were not filled in correctly and were excluded, totaling a final sample of 96 students (66.2\%). After analyzing the data, it was observed the predominance of students aged 18 to 29 years and those with family income of 1 to 4 minimum wages. Most of the students were in grade 5, the final year of graduation (Table 1 ).

The data obtained, $57.2 \%$ of university students stated that they did not present any pathology. Among the most prevalent diseases cited were migraine, followed by headache and anxiety (Table 2). The use of NSAIDs for pain and inflammation was mentioned by $94.7 \%$ of the students, where the main ones were: dipyrone, paracetamol and ibuprofen. Among the most frequent algic processes that led to the use of these NSAIDs, the following stand out: headache, colic, migraine; In addition, $5.2 \%$ of them stated that dysmenorrhea was the cause of anti-inflammatory use (Table 3). Another justification for the use of NSAIDs was evaluated and it was observed that $75 \%$ of the students reported using
Table 1: Socio-economic and demographic characteristics of pharmacy college students and their association with use NSAIDs.

\begin{tabular}{cccc}
\hline Characteristics & $\begin{array}{c}\mathrm{n}(\%) \\
96\end{array}$ & $\begin{array}{c}\text { Use NSAIDs } \\
\mathrm{n}=91(94,7 \%)\end{array}$ & P Value \\
\hline Age group (years) & & & 0,0005 \\
$18-29$ & $87(90,6)$ & $84(96,5)$ & \\
$30-39$ & $6(6,2)$ & $6(100)$ & \\
$>39$ & $3(3,1)$ & $1(33,3)$ & 0,19 \\
Family income (MW) & & & \\
$<1$ & $13(13,5)$ & $13(100)$ & \\
$1-4$ & $64(66,6)$ & $61(95,3)$ & \\
$5-10$ & $18(18,7)$ & $16(88,8)$ & \\
$>10$ & $1(1)$ & $1(100)$ & \\
& & & \\
Graduation period (year) & & $14(77,7)$ & \\
$1^{\circ}$ & $18(18,7)$ & $12(100)$ & \\
$2^{\circ}$ & $12(12,5)$ & $16(100)$ & \\
$3^{\circ}$ & $16(16,6)$ & $22(100)$ & \\
$4^{\circ}$ & $22(22,9)$ & $27(96,4)$ & \\
$5^{\circ}$ & $28(29,1)$ &
\end{tabular}

MW $=$ minimum wage. $\mathrm{n}=$ population

Table 2: Diseases referred by pharmacy college students and use of NSAIDS.

\begin{tabular}{cccc}
\hline Characteristics & $\begin{array}{c}\mathrm{n}(\%) \\
96\end{array}$ & $\begin{array}{c}\text { Use NSAIDs } \\
\mathrm{n}=\mathbf{9 2}(95,8 \%)\end{array}$ & PValue \\
\hline Diseases presented & & & 0,42 \\
Anxiety & $11(11,4)$ & $9(81,8)$ & \\
Headache & $17(17,7)$ & $17(100)$ & \\
Diabetes & $2(2)$ & $2(100)$ & \\
Dysmenorrhea & $6(6)$ & $6(100)$ & \\
Migraine & $20(20,8)$ & $20(100)$ & \\
Gastritis & $7(7,2)$ & $7(100)$ & \\
Hypertension & $1(1)$ & $1(100)$ & \\
No diseases & $55(57,2)$ & $53(96,3)$ & \\
\hline
\end{tabular}

them to improve well-being and $53.1 \%$ to avoid academic absenteeism. The purchase of drugs was mainly through pharmacies and friends, with $97.9 \%$ and $8.3 \%$, respectively, and $92.7 \%$ were made without a prescription, which shows a high rate of self-medication for university students.

The frequency of NSAID use was evaluated and it was found that the majority of students used non-steroidal anti-inflammatory drugs (NSAIDs) 1 to 3 times a month, with high frequency of use being 6-10 times $(5.2 \%)$ and $>10(5.2 \%)$ were less prevalent (Graph 1).

In relation to the menstrual cycle, most rated as regular and lasting $<7$ days. 51\% reported the use of pre-menstrual and menstrual periods during the pre-menstrual period, while in the menstrual period the rate was $65.6 \%$ among university students (Table 4 ). Regarding the side effects, $23 \%$ of the students reported some effect, the most frequent being the gastrointestinal ones, among them, nausea (14.5\%) and heartburn (10.4\%). Others important effects were reported as insomnia, agitation, palpitation, increased blood pressure and headache, but with incidence less than 5\% (Graph 2). 
Candido, et al:: Use of Anti-Inflammatory Agents by Pharmacy College Students

Table 3: List of NSAIDs most used by pharmacy college students and main corresponding situations.

\begin{tabular}{|c|c|c|c|c|c|}
\hline Characteristics & $\begin{array}{c}\text { n (\%) } \\
96\end{array}$ & $\begin{array}{c}\text { Dipyrone } \\
\mathrm{n}=62(64,5)\end{array}$ & $\begin{array}{l}\text { Ibuprofen } \\
n=51(53,1)\end{array}$ & $\begin{array}{c}\text { Paracetamol } \\
n=52(54,1)\end{array}$ & $P$ Value \\
\hline \multicolumn{6}{|l|}{$\begin{array}{c}\text { Most frequent algic } \\
\text { processes }\end{array}$} \\
\hline Headache & $66(68,7)$ & $45(68,1)$ & $37(56)$ & $43(65,1)$ & 0,001 \\
\hline Cramp & $60(62,5)$ & $40(66,6)$ & $35(58,3)$ & $36(60)$ & 0,30 \\
\hline Migraine & $38(39,5)$ & $31(81,5)$ & $22(57,8)$ & $21(55,2)$ & 0,09 \\
\hline Dysmenorrhea & $5(5,2)$ & $3(60)$ & $2(40)$ & $3(60)$ & 0,60 \\
\hline \multicolumn{6}{|l|}{ Mensal use } \\
\hline $1-3$ & $64(66,6)$ & $40(62,5)$ & $33(51,5)$ & $35(54,6)$ & 0,16 \\
\hline $4-6$ & $17(17,7)$ & $14(86)$ & $11(64,7)$ & $13(76,4)$ & 0,36 \\
\hline $6-10$ & $5(5,2)$ & $3(60)$ & $4(80)$ & $2(40)$ & 0,44 \\
\hline$>10$ & $5(5,2)$ & $3(60)$ & $2(40)$ & $2(40)$ & 0,60 \\
\hline Never & $5(5,2)$ & 0 & 0 & 0 & 0,0007 \\
\hline \multicolumn{6}{|l|}{ Main side effects } \\
\hline Heartburn & $10(10,4)$ & $7(70)$ & $7(70)$ & $5(50)$ & 0,80 \\
\hline Nausea & $13(13,5)$ & $11(84,6)$ & $9(69,2)$ & $9(69,2)$ & 0,72 \\
\hline Self medication & $88(91,6)$ & $58(65,9)$ & $49(55,6)$ & $52(59)$ & 0,01 \\
\hline
\end{tabular}

OBS: Questions with multiple options resulting in variable percentages.

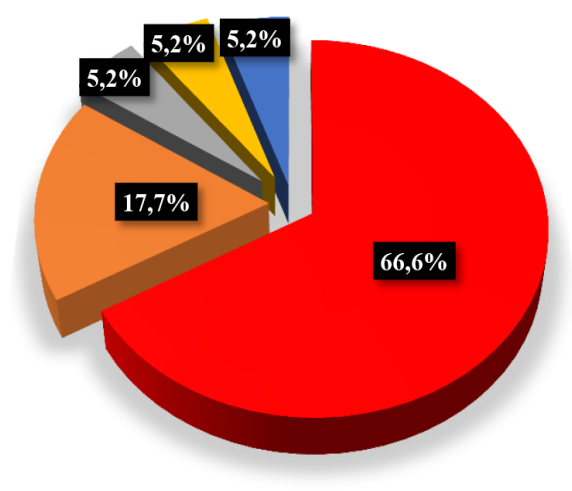

-1-3 times/month

4-6 times/month

6-10 times/month

m $>10$ times $/$ month

Never

Graph 1: Frequency of monthly use of NSAIDs by pharmacy college students.

Table 4: Use of NSAIDs by pharmacy college students in the pre-menstrual and menstrual periods according to the characteristics of the cycle.

\begin{tabular}{|c|c|c|c|c|c|}
\hline Characteristics & $\begin{array}{c}\text { n (\%) } \\
96\end{array}$ & $\begin{array}{c}\text { Use AINEs } \\
\text { pre-menstrual } \\
\text { period } \\
n=49(51)\end{array}$ & $P$ Value & $\begin{array}{c}\text { Use AINEs } \\
\text { menstrual } \\
\text { period } \\
n=63(65,6)\end{array}$ & $P$ Value \\
\hline Menstrual Cycle & & & 0,10 & & 0,28 \\
\hline Regular & $66(68,7)$ & $30(45,4)$ & & $41(62,1)$ & \\
\hline Irregular & $30(31,2)$ & $19(63,3)$ & & $22(73,3)$ & \\
\hline Menstrual Flow & & & 0,72 & & 0,41 \\
\hline$<7$ days & $69(71,8)$ & $36(52,1)$ & & $47(68,1)$ & \\
\hline$>7$ days & $27(28,1)$ & $13(48,1)$ & & $16(59,2)$ & \\
\hline
\end{tabular}

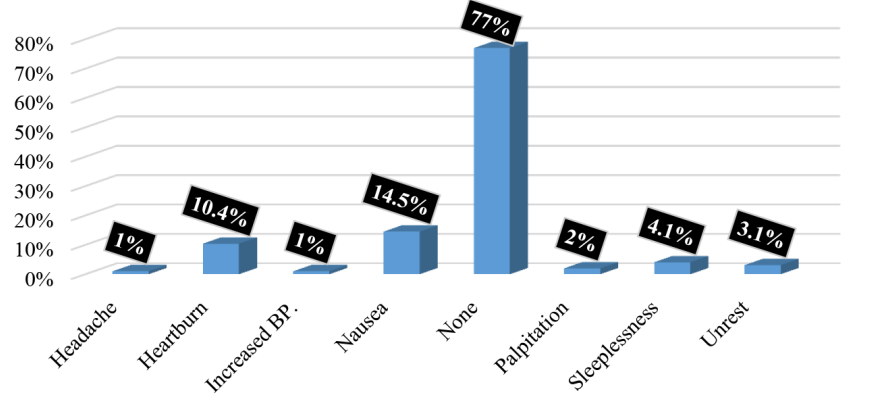

Graph 2: Side effects presented by pharmacy college students after the use of NSAIDs.

OBS: Some questions had multiple options that universities could select and therefore the sum of percentages is not always $100 \%$. BP. = Blood pressure.

\section{DISCUSSION}

The results indicate a possible non-correlation between the rational use of NSAIDs and the graduation period by university pharmacy students, where it was found that NSAIDs in students $>39$ years and in the 1st year of graduation had the lowest rates of use $(p=0.0005)$ and $(p=0.01)$, respectively, regarding the use of high and self-medication among university students in more advanced periods of academic training.

Studies suggest that factors such as self-confidence, due to theoretical and practical knowledge acquired during undergraduate courses, may explain self-medication among students in advanced stages of academic training. ${ }^{17}$ In one of these studies, it was evidenced that the consumption of NSAIDs was higher as the level of graduation increased $(p=0.001)$, similar to the present study. ${ }^{18}$ Another factor that may be related to the high use of analgesics goes beyond the knowledge and academic training and self-confidence generated by them, which is the psychological need to prevent or reduce pain caused by the hypothesis of self-medication. ${ }^{19}$ 
Drug consumption among university students is due to several factors, including those related to sociocultural issues. One study found that the predominant age group was 21-30 years, but there was no significant difference on the irrational use of the drugs in this study in relation to the age group. ${ }^{20}$ The family income was evaluated where the most frequent one was in the range superior to 4 minimum salaries (47.4\%), and less frequent was with up to 1 minimum wage (9.1\%). Another research evidenced a very different result of this study, where $70 \%$ of university students reported having income $>10$ minimum wages, and such divergences may be related mainly to regional economic factors. ${ }^{21}$

The findings show that in the case of diseases referred to as migraine, headache, colic, diabetes, hypertension, anxiety, most of the university students used these drugs regardless of the presence or absence of diseases. These results converge with other studies on the use of NSAIDs among university students in the algic processes presented in relation to frequency and irrationality.

A study carried out at a university in Madrid, with the majority female population $(72.77 \%)$, showed that the most used drugs were ibuprofen $45.9 \%$ and paracetamol $26.7 \%$ for relief of headaches, muscle cramps and colic menstrual periods. ${ }^{22}$ In Ethiopia, headache (51.56\%), cold (44.80\%), dysmenorrhoea $(20.30 \%)$, and paracetamol were the most commonly used drugs $(48,44 \%)$ and other NSAIDs (42.20\%). ${ }^{23-24}$

In a study of migraine in university students conducted in the United States, $24.8 \%$ reported migraine and $77.1 \%$ used NSAIDs, only $13 \%$ used prophylaxis for the pathology, more than $80 \%$ reported relief of symptoms showing therapeutic efficacy of this pharmacological class. ${ }^{25}$ In several studies conducted in Brazil, headache was the main reason for drug use by university students, and rates of $92.8 \%, 86.6 \%$ and $67 \%$ were found in three studies, developed in the states of Paraná, Minas Gerais and Paraíba, respectively. The main drugs mentioned were those belonging to the analgesic/anti-inflammatory class. ${ }^{15,26-27}$

A high rate of self-medication of $92.7 \%$ among university pharmacists was verified in the present study. These findings corroborate with other studies on the use of analgesic drugs, absenteeism and loss of quality of work activity. Migraine was a significant cause of absenteeism and decreased productivity of daily activities by medical students in the United States, and the use of NSAIDs reached $77.1 \%{ }^{25}$ Dysmenorrhoea was described as another important reason for absenteeism in $48.4 \%$ of university students, in whom several symptoms were presented, nervous irritation, headache, mastalgia, among others, 79\% of students used drugs to relieve menstrual pain. ${ }^{16}$

The present research showed that the acquisition of NSAIDs by university students was done mainly through pharmacies (97.9\%) and friends (8.3\%), where $92.7 \%$ obtained medications without prescription, which shows a high index self-medication by university students. These results corroborate with other studies where the main form of acquisition of analgesics was in pharmacies, through friends, neighbors and relatives or medicines remaining from previous treatments $(26 \%))^{21,28}$

In Malaysia, a survey showed that the prevalence of self-medication was $80.9 \%$ among students. A number of studies have shown a varied but high prevalence of self-medication in pharmacy students in Pakistan $67-76 \%$, Turkey $45 \%$, Croatia $88 \%$ and Hong Kong $94 \% .{ }^{29-30}$ In a survey in South India involving 440 medical students, of these 250 (56.8\%) women, self-medication was reported by $75.3 \%$ of university students. ${ }^{31}$ Thus, self-medication is a widespread practice among university students, even among undergraduate health courses where, through specific training, less use can be expected.

Regarding the frequency of use of NSAIDs, the findings showed an irrational and unsafe consumption in the studied population, 1-3 times a month, characterized as chronic use, but which is similar to other studies in several places in the world and in Brazil. A survey of students in pharmacy, dentistry, medicine and nursing found that the frequency of use of 1 to 3 times was $88.8 \%$ and $>3$ times $11.2 \%$. $^{32}$ The time taken to use NSAIDs in another study showed that $59 \%$ of the patients used or used for less than 7 days, $19 \%$ from 8 to 15 days and $21 \%$ of a month. In Spain, a study on self-medication in university students showed that $49.36 \%$ of students were taking medicines rarely, $37.41 \%$ once a month and $7.4 \%$ taking medicines every day, being the main analgesics and anti-inflammatory drugs. ${ }^{33}$ This also refers to cultural and academic factors that may be present in the training of university students, where this country has been one of the worldwide references in training for the rational use of medicines with pharmaceutical care strategies. ${ }^{34}$

The results regarding the use of NSAIDs in the pre-menstrual and menstrual periods, evidenced a high use in the menstrual period, by university students who had irregular menstrual cycle and with flow $<7$ days. Such findings resemble other similar studies. A study evaluating menstrual discomfort showed that the majority of women evaluated had irregular menstrual cycles (75\%), with flow duration of 3 to 5 days (74.7\%). Colic and low back pain were the most frequent symptoms in this period, in $63.1 \%$ of the cases. ${ }^{35}$ Another study on premenstrual syndrome in nursing students found that $69.9 \%$ of the students had regular cycles, but they reported symptoms such as mastalgia (77\%), cramps (67.9\%), edema (49.2\%), and headache (43.5\%). ${ }^{36}$ Reflections on influencing factors for menstrual irregularities should be better investigated whether of physiological origin such as ovarian (polycystic ovary) changes, whether they are food or mood changes, which influence the whole cycle, even in the duration of blood flow considered adequate (<7 days).

About 23\% of the respondents reported gastrointestinal disorders such as heartburn and nausea among the main adverse effects to NSAIDs, not differing from other studies. In a study in Brazil, $20 \%$ of the students said they presented abdominal pain in $46 \%$ of the cases, and the gastrointestinal effect was reported as the predominant factor. ${ }^{37}$ In another study, $10 \%$ had stomach pain, nausea and headache. ${ }^{31}$ The secondary adverse effects reported by university students in the present study, although less frequent were significant, including risk and quality of life loss such as increased blood pressure, arrhythmia, insomnia, headache and restlessness. ${ }^{38}$ Such effects may be related to chronic use. It was thus found that the adverse effects presented in an expressive part of those who used NSAIDs caused disorders that impacted the quality of life and often generated symptoms that were the reason for the primary use of these drugs such as headache.

\section{CONCLUSION}

In synthesis, the present study demonstrated that NSAIDs are the most frequently used drugs among students of female pharmacy colleges for algic processes such as headache, menstrual cramps, migraine and others referred to as possible hormonal changes. High anti-inflammatory use was observed, mainly by self-medication. The most commonly used drugs were dipyrone and paracetamol. Self-medication by university students refers to a chronic and unsafe use profile, which leads to frequent gastrointestinal adverse effects. Despite being a drug class considered safe at usual therapeutic doses, its use was worrisome. Studies are still needed to evaluate the possible impacts of the use of these drugs in the medium and long term in this population.

\section{ACKNOWLEDGEMENT}

We are thankful to the various researchers from our Pharmacy and Innovation Group at Quixadá Catholic University Center. 


\section{CONFLICT OF INTEREST}

The authors declare no conflict of interest.

\section{ABBREVIATIONS}

NSAIDs: Non-Steroidal Anti-Inflammatory Drugs; COXs: Cyclooxygenases; DRPs: Drug Related Problems; SPSS: Statistical Package for the Social Sciences.

\section{REFERENCES}

1. Pharmaceutical Research Industry Association. Guia Interfarma. (Cited 2016 Set). Available from: https://www.interfarma.org.br/guia/impressora.php

2. Pereira LA. Brazil to be fifth largest pharmaceutical market in 2015. Pharm Bras. 2012;12(86):13.

3. Geller M, Krymchantowski AV, Steinbruch M, Cunha KS, Ribeiro MG, Oliveira $L$, et al. Diclofenac use in clinical practice: Review of therapeutic evidence and pharmacological actions. Rev Bras Clin Med. 2012;10(1):29-38.

4. Duong M, Salvo F, Pariente A, Abouelfath A, Lassalle R, Droz C, et al. Usage patterns of 'over-the-counter' vs. prescription-strength nonsteroidal anti-inflammatory drugs in France. Br J Clin Pharmacol. 2014;77(5):887-95.

5. Pountos I, Georgouli T, Bird H, Giannoudis PV. Nonsteroidal anti-inflammatory drugs: Prostaglandins, indications, and side effects. Int J Interferon Cytokine Mediat Res. 2011;3(1):19-27.

6. Carli ML. Effectiveness of Piroxicam and Low Level Laser in the Treatment of Temporomandibular Joint Arthralgia. A Double-blind clinical randomized trial. 2012. 106 f. Thesis (Doctorate in Dentistry). University of São Paulo.

7. Schellack N, Schellack G, Fourie J. A review of Non-Steroidal Anti-inflammatory Drugs. South African pharmaceutical journal. Suid-Afrikaanse tydskrif vir apteekwese. 2015;82(3):8-18

8. Nascimento DM, Pigoso AA. Drug interaction between antihypertensive and non-steroidal anti-inflammatory drugs. Rev Cient FHO Uniararas. 2013;1(1):14-7.

9. Batlouni M. Nonsteroidal anti-inflammatory drugs: Cardiovascular, cerebrovascular and renal effects. Arq Bras Cardiol. 2010;94(4):556-63.

10. Costa KS, Barros MB, Francisco PM, César CL, Goldbaum M, Carandina L. Use of medication and associated factors: A population-based study in Campinas, São Paulo State, Brazil. Cad Saúde Pública. 2011;27(4):649-58.

11. Barreiros FF. Food, stress and menstrual cycle. Thesis, Faculty of Pharmaceutical Sciences, University Fernando Pessoa. Porto, Portugal. 2015.

12. Souza LW, Damasceno AK, Lopes EM, Aquino PD. Factors related to premenstrual syndrome in nursing students. Rev Min Enfem. 2010;14(4):548-53.

13. Silveira AD, Vieira E, Leão DM, Nicorena BP, Ferreira R, Longoria SE. Pre-menstrual tension syndrome observed in users of the municipal health clinic for women. Enferm Glob. 2014;13(35):63-73.

14. Mogil JS. Sex differences in pain and pain inhibition: Multiple explanations of a controversial phenomenon. Nat Rev Neurosci. 2012;13(12):859-66.

15. Silva LB, Piveta LN, Girotto E, Guidoni CM. Drug consumption and practice of self-medication by students from health-related courses at the State University of Londrina. Rev Espac Saude. 2015;16(2):27-36.

16. Oliveira Nunes JM, Amaral Rodrigues J, Freitas Moura MS, Batista SR Coutinho SK, Hazime FA, et al. Prevalence of dysmenorrhea in university students and its relation to school absenteeism, physical exercise and use of medication. Rev Bras Promoc Saude, Fortaleza. 2013;26(3):374-9.

17. Rosse WJ, Mouro VG, Carvalho CA. Self-medication profile in students of pharmacy Univiçosa, Viçosa, MG. Anais Simpac. 2015;2(1)
18. Pandya RN, Jhaveri KS, Vyas FI, Patel VJ. Prevalence, pattern and perceptions of self-medication in medical students. Int J Basic Clin Pharmacol. 2013;2(3):275-80

19. Khantzian EJ. The self-medication hypothesis of addictive disorders: focus on heroin and cocaine dependence. Am J Psychiatry. 1987:65-74.

20. DhamerT, Dal-Molin AP, Helfer AP, Carneiro M, Possuelo LG, Kauffmann C, et al. Self-medication in academic course graduate of health in a private university of the state of Rio Grande do Sul. Rev Epidemiol Control Infect. 2012;2(4):138-40.

21. Schuelter-Trevisol F, Trevisol DJ, Jung SG, Jacobowski B. Self-medication among university. Rev Bras Clin Med. 2011;9(6):414-7.

22. Ranilla BG, Serrano LD. Study of drug consumption in university students. Reduca. Seccion Congresos Alumnos. 2014;6(1):1-10.

23. Gutema GB, Gadisa DA, Kidanemariam ZA, Berhe DF, Berhe AH, Hadera MG, et al. Self-medication practices among health sciences students: The case of Mekelle University. J Appl Pharma Sci. 2011;1(10):183

24. Abay SM, Amelo W. Assessment of Self-medication practices among medical, pharmacy, health science students in Gondar University, Ethiopia. J Young Pharma. 2010;2(3):306-10.

25. Johnson H, Guhl G, Arora J, Walling A. Migraine in Students of a US Medical School. Fam Med. 2014:46(8):615-9.

26. Silva AL. Self-medication profile academics in the college pharmacy in public institution of higher education in the municipality of João Pessoa-PB. Department of Pharmaceutical Sciences, Health Sciences Center, Federal University of Paraíba, Brazil. 2015. [cite 2018 Apr 10]. Available from: http://rei.biblioteca. ufpb.br/jspui/bitstream/123456789/879/1/ALSS24022015.pdf.

27. Luz FA, Morais-Silva G, Borges HD, Fernandes-Santos J, Moura LD, Cândido $\mathrm{TO}$, et al. Comparative profile of self-medication among students of the Federal University of Uberlândia. Horiz Cient. 2014;8(1).

28. Chagas OF, Éckeli FD, Bigal ME, Silva MO, Speciali JG. Study of the use of analgesics by patients with headache at a specialized outpatient clinic (ACEF). Arq Neuro-Psiquiatr. 2015;73(7):586-92.

29. Ali SE, Ibrahim MI, Palaian S. Medication storage and self-medication behaviour amongst female students in Malaysia. Pharm Pract (Granada, Internet). 2010; 8(4):226-32

30. Naqvi AA, Ahmad R, Qadeer O, Khan MH, Nadir MN, Alim M. The Prevalence of Self Medication and the Factors influencing its Practice in Pharmacy Students of Karachi, Pakistan: A mix mode study. J Young Pharm. 2016:8(3):230-8.

31. Kumar N, Kanchan T, Unnikrishnan B, Rekha T, Mithra P, Kulkarni V, et al. Perceptions and practices of self-medication among medical students in coastal South India. PLoS One. 2013:8(8):72247.

32. Silva MG, Lourenço EE. Indiscriminate use of anti-inflammatories in Goiânia-GO and Bela Vista-GO. Revista Científica do ITPAC Araguaína. 2014;7(4).

33. Carabias Martín F. Automedicación en universitarios. Thesis, Facultad de Farmacia Universidad de Salamanca, Salamanca, Espanha. 2011.

34. Hernández DS, Castro MM, Dáder MJ. Programa Dáder. Método Dáder. Guía de seguimento farmacoterapéutico. Granada: Universidade de Granada. 2007.

35. Ferreira PR, Silva Barbosa EM. Evaluation of the perception of menstrual discomforts among women attending a teaching and health unit. Rev Pesq Saude. 2012;1(1):117-30.

36. Luz JM, Osório SM, Santos IM, Piauilino YM, De Barros VL, Nicola Al. Consequences of Premenstrual Syndrome in Nursing Academics. RETEP. 2015;7(2):1537-41

37. Karyna HK, Almeida FA, Jorge RJ. Study on self-medication when using NSAIDs in the city of Valparaiso de Goiás. Rev Saúde Desenvolv. 2016;9(5):142-53.

38. US Food and Drug Administration [FDA]. Medication guide for non-steroida anti-inflammatory drugs (NSAIDs). [cite 2018 Apr 10]. Available from: https:// www.fda.gov/downloads/drugs/drugsafety/ucm089162.pdf.

Article History: Submission Date : 14-02-2018; Revised Date : 23-05-2018; Acceptance Date : 08-06-2018.

Cite this article: Cândido JLL, Maia AKSN, Cunha GMN, Girão Junior FJ, Fonteles MMF, Batista JMM. Use of Anti-Inflammatory Agents by Pharmacy College Students: Correlation of the Menstrual Cycle and Self-medication. JYoung Pharm. 2018;10(4):466-70. 